\title{
The conceptual of re-design propulsion system and ship electricity management to reduce waste emission
}

\author{
Abdul Rahman *, Antariksa, Bambang Semedi and Slamet Wahyudi \\ University of Brawijaya, Malang Indonesia. \\ Global Journal of Engineering and Technology Advances, 2021, 06(02), 104-113 \\ Publication history: Received on 10 January 2021; revised on 11 February 2021; accepted on 15 February 2021
}

Article DOI: https://doi.org/10.30574/gjeta.2021.6.2.0021

\begin{abstract}
Climate change is a serious threat to the environment and socioeconomic globally. Climate change is caused by natural processes and due to human activities that have resulted in long-term climate fluctuations and even globally over the past few decades, the climate has experienced a fairly rapid rise in average temperatures. Climate change is mainly caused due to ozone depletion which results in changes in greenhouse effect conditions. The International Maritime Organization (IMO) has adopted standards to reduce sulfur pollution from ships. The majority of naval warships today use conventional mechanical propulsion systems where the power from the main propulsion is transmitted to the propeller through gearboxes. The ships owned by the Navy almost all still use conventional thrust systems with diesel engine starters. With a conventional support system. The latest innovation in the support system that has been carried out, namely on the United States Navy warship TAKE-1 (the destroyer ship), whereby changing the support system from conventional to electricity with the concept of Integrated Fully Electric Propulsion (IFEP) can reduce fuel use by $10 \%$ to $25 \%$. IFEP application if applied to ships of the Navy, will obtain a very large benefit in overcoming environmental problems namely reducing air pollution.
\end{abstract}

Keywords: Integrated Fully Electric Propulsion (IFEP); Concept on Navy ships

\section{Introduction}

Climate change is a serious threat to the environment and socioeconomic globally. Climate change is caused by natural processes and due to human activities that have resulted in long-term climate fluctuations and even globally over the past few decades, the climate has experienced a fairly rapid rise in average temperatures. Climate change is mainly caused by the depletion of the ozone layer which results in changes in greenhouse effect conditions. The greenhouse effect plays an important role in protecting the survival of living things on earth. Referred to as a protector because water vapor, $\mathrm{CO}_{2}$ gas, methane gas, and other types of gas in balanced concentrations function to hold the sun's heat energy that radiates its light to the earth, then the surface is always warm so that living things on earth do not freeze due to cold. But the greenhouse effect will have a negative impact when there is an increase in gas concentration.

The maritime industry contributes to environmental changes related to climate change. Today there are around $80 \%$ of international trade and the movement of goods carried by ships, where these ships use fossil fuels as a source of power for the main driving machine as well as for the engine generating electricity on the ship that causes exhaust emissions from these activities. Exhaust emissions from ship activities contribute to the increase in gas concentrations of gaseous pollutants including carbon dioxide, nitrogen oxides, sulfur dioxide, petroleum hydrocarbons, and particulates, which if not controlled will accelerate the increase in gas concentration in the atmosphere causing global warming. Departing from these conditions, efforts are needed to control climate change to reduce negative impacts on humans or find possible ways to adapt that make sense to climate change.

\footnotetext{
* Corresponding author: Abdul Rahman

University of Brawijaya, Malang Indonesia.
} 
The International Maritime Organization (IMO) has adopted standards to reduce sulfur pollution from ships. These standards require a reduction in sulfur content in fuel from $3.50 \%$ mass of sulfur (after January 1,2012 ) to $0.50 \%$ mass of sulfur (after January 1, 2020). This 2020 standard can be postponed until January 1, 2025, based on the results of a regulatory review that is currently underway. The IMO Maritime Environmental Protection Committee (MEPC) announced that member country delegations agreed on a target to cut the overall $\mathrm{CO}_{2}$ output of the shipping sector by 50 percent by 2050 .

Reducing fuel use can be done by sailing ships at lower speeds to increase efficiency and reduce emissions significantly. A $10 \%$ reduction in speed will reduce fuel use by about $20 \%$ in units of distance. The rate of increase in emissions can also be done by rearranging the configuration of the thrust system and rearranging the management of the power plant on ships that still use the configuration of the boost system and management of the conventional power plant. These efforts can reduce carbon dioxide $\left(\mathrm{CO}_{2}\right)$ emissions including pollutants such as sulfur oxide (SOx), nitrogen oxides (NOX), and particulate matter (PM).

The latest innovation in the propulsion system that has been carried out on the United States Navy warship TAKE-1 (the destroyer ship), which by changing the propulsion system from conventional to electricity with the concept of Integrated Fully Electric Propulsion (IFEP) can reduce fuel use by $10 \%$ up to $25 \%$. This electric propulsion system will increase the efficiency of fuel use thereby reducing air pollution. Another advantage of the application of IFEP compared to conventional propulsion systems is that they obtain flexibility, the ability to withstand and reduce operational costs, and efficient engine loading at every speed of the ship's operations.

IFEP application if applied to ships of the Navy, will benefit greatly in overcoming environmental problems, namely reducing air pollution. Thus the Navy will contribute greatly in participating in overcoming environmental problems. Considering the importance of this problem, the researchers wanted to research how to design an existing shipbuilding system with a conventional system into a ship with an Integrated Fully Electric Propulsion support system, and how to redesign the ship's electrical load management using Variable Speed Drive (VSD).

\section{Material and methods}

Based on critical reviews or critical studies that have been done in several previous similar studies, it can be said that aspects of the discussion about Environment, Economy aspects, Energy Efficiency, and Variable Speed Drive (VSD) have been widely discussed in previous studies, but are still being done partially so that there is one gap that can be developed and become a GAP from previous research, namely how to analyze a ship's support system with the Integrated Fully Electric Propulsion (IFEP) model and the relationship between variables Environment, Economy, Energy Efficiency, and Variable Speed Drive (VSD) as a system that interacts with the reconfiguration of the support system with the Integrated Fully Electric Propulsion (IFEP) model and comprehensive management of the ship's electrical load.

\subsection{Propulsion System}

The ship propulsion system is a series of systems on a ship that is used to drive a ship. In its operations at sea, a ship must have the ability to maintain official speed (Vs) as planned. This means that the ship must have a propulsion (drive) system design that can overcome the overall drag forces (total resistance) that occur to meet the service speed standards. In general, the Ship Propulsion System consists of 3 (three) main components, including (a) Main Engine (main engine); (b) Transmission System and (c) Propulsor. These three main components constitute a unity which in the planning process cannot be reviewed separately. Mistakes in the design, will bring "consequences" are very large for the following conditions:

- Failure to achieve planned ship service speed.

- Fuel oil consumption is inefficient.

- The economic value of the ship decreases.

- Effect on the level of vibration that occurs in the hull, etc.

The configuration of the three main components of the propulsion system is greatly influenced by the design of the ship's function itself, as well as how the mission must be carried out in its operations at sea.

\subsection{Global Warming}

Global warming is a process of increasing the average temperature of the atmosphere, sea, and land of the Earth. The average global temperature on the Earth's surface has risen $0.74 \pm 0.18^{\circ} \mathrm{C}\left(1.33 \pm 0.32^{\circ} \mathrm{F}\right)$ over the past hundred years. 
The Intergovernmental Panel on Climate Change (IPCC) concluded that "most of the increase in global average temperatures since the mid-20th century is most likely due to increased concentrations of greenhouse gases due to human activities" through the greenhouse effect.

The climate model referred to by the IPCC project shows global surface temperatures will increase 1.1 to $6.4^{\circ} \mathrm{C}(2.0$ to $11.5^{\circ} \mathrm{F}$ ) between 1990 and 2100 . The difference in estimates is due to the use of different scenarios regarding greenhouse gas emissions in the future, as well as different climate sensitivity models. Although most research has focused on the period up to 2100, warming and rising sea levels are expected to continue for more than a thousand years even though the level of greenhouse gas emissions has stabilized.

Rising global temperatures are expected to cause other changes such as rising sea levels, increasing intensity of extreme weather phenomena, as well as changes in the amount and pattern of precipitation. Other consequences of global warming are the impact of agricultural output, the loss of glaciers, and the extinction of various types of animals.

Some of the things that scientists still doubt are about the amount of warming that is expected to occur in the future, and how the warming and the changes that occur will vary from one region to another. Until now there has been political and public debate in the world about what, if any, action must be taken to reduce or reverse further warming or to adapt to the consequences. Most governments in the world have signed and ratified the Kyoto Protocol, which leads to the reduction of greenhouse gas emissions.

\subsection{Greenhouse Effect}

The greenhouse effect, which was first proposed by Joseph Fourier in 1824, is the process of heating the surface of a celestial body (mainly planets or satellites) due to its composition and atmospheric state. Mars, Venus, and other atmospheric bodies (such as Saturn's natural satellite, Titan) also have a greenhouse effect. this paper only discusses the influence on Earth.

The greenhouse effect can be used to designate two different things: the natural greenhouse effect that occurs naturally on earth, and the greenhouse effect that occurs due to human activities. The increased greenhouse effect due to human activities is the most accepted by all.

The greenhouse effect is caused by increasing concentrations of carbon dioxide $\left(\mathrm{CO}_{2}\right)$ and other gases in the atmosphere. The increased concentration of $\mathrm{CO}_{2}$ gas is caused by the burning of many fuels of oil, coal, and other organic fuels that exceeds the ability of plants and the sea to absorb them. Energy entering Earth:

$25 \%$ is reflected by clouds or other particles in the atmosphere

$25 \%$ absorbed by the cloud

$45 \%$ is absorbed by the earth's surface

$10 \%$ is reflected by the earth's surface

The absorbed energy is reflected in the form of infrared radiation by clouds and the earth's surface. But most of the infrared emitted by the earth is blocked by clouds and CO2 and other gases, to be returned to the earth's surface. Under normal circumstances, the greenhouse effect is needed, with the greenhouse effect the temperature difference between day and night on earth is not too much different. In addition to $\mathrm{CO}_{2}$ gas, which can cause greenhouse effects are sulfur dioxide, nitrogen monoxide (NO), and nitrogen dioxide $\left(\mathrm{NO}_{2}\right)$ as well as some organic compounds such as methane gas and chlorofluorocarbons (CFCs). These gases play an important role in increasing the greenhouse effect.

The rising temperature of the earth's surface will result in extreme climate change on earth. This can result in the disruption of forests and other ecosystems, thereby reducing its ability to absorb carbon dioxide in the atmosphere. Global warming causes the melting of icebergs in the polar regions which can lead to rising sea levels. The greenhouse effect will also cause an increase in seawater temperatures, resulting in several small islands sinking in the archipelago, which has a profound change effect.

According to simulation calculations, the greenhouse effect has increased the earth's average temperature $1-5^{\circ} \mathrm{C}$. If the tendency to increase greenhouse gases remains as it is now will cause an increase in global warming between $1.5-4.5^{\circ}$ $\mathrm{C}$ around 2030. With the increase in the concentration of $\mathrm{CO}_{2}$ gas in the atmosphere, the more heatwaves reflected from the earth's surface are absorbed by the atmosphere. This will cause the surface temperature of the earth to increase. 


\subsection{Climate change}

Climate change is a long-term change in the distribution of weather patterns statistically over a while from decades to millions of years. This term can also mean changes in average weather conditions or changes in the distribution of average weather events, for example, the number of extreme or fewer extreme weather events. Climate change is limited to a certain region or can occur in all regions of the Earth.

In its current use, especially in environmental policies, climate change refers to modern climate change. These changes can be classified as anthropogenic climate change or more commonly known as global warming or anthropogenic global warming.

Climate change occurs when changes in the Earth's climate system produce new weather patterns that last for at least several decades, and perhaps for millions of years. The climate system consists of five interacting parts, the atmosphere (air), hydrosphere (water), cryosphere (ice and permafrost), biosphere (living things), and lithosphere (earth's crust and upper mantle). The climate system receives almost all of its energy from the sun, with a relatively small amount from the Earth's interior. The climate system also provides energy into space. The balance of energy entering and leaving, and energy traveling through the climate system, determines the Earth's energy budget. When the incoming energy is greater than the outgoing energy, the earth's energy budget is positive and the climate system heats up. If more energy comes out, the energy budget is negative and the earth cools down.

Human activities can also change the Earth's climate and currently encourage climate change through global warming. There is no general agreement in scientific documents, media, or policies regarding the exact term to be used to refer to anthropogenically forced changes; either "global warming" or "climate change" can be used.

\subsection{Air pollution}

Air pollution is the presence of one or more physical, chemical, or biological substances in the atmosphere in quantities that can endanger human, animal, and plant health, disrupt aesthetics and comfort, or damage property. Air pollution can be caused by natural sources and human activities. Some definitions of physical disorders such as noise pollution, heat, radiation, or light pollution are considered air pollution. The nature of air causes the effects of air pollution can be direct and local, regional, and global.

Air pollutants can be divided into two namely, primary pollutants and secondary pollutants. Primary pollutants are pollutant substances that are generated directly from sources of air pollution. Carbon monoxide is an example of primary air pollutants because it is the result of combustion. Secondary pollutants are pollutant substances formed from the reaction of primary pollutants in the atmosphere. The formation of ozone in photochemical smog is an example of secondary air pollution. Sources of air pollution can be classified as follows:

Human activities

- Transportation

- Industry

- Power plants

- Combustion (fireplace, stove, furnace, incinerator with various types of fuel) including traditional biomass burning factory exhaust gases that produce harmful gases such as CFCs

Natural sources

- Volcano

- Swamps

- Forest fires

- Denitrification

- Under certain conditions, vegetation can produce significant volatile organic compounds that can react with anthropogenic pollutants to form secondary pollutants 
Other sources

- Transportation

- Gas tank leak

- $\quad$ The methane gas from landfills

- Organic solvent vapors

\section{Results and discussion}

Based on the focus and purpose of the study that discusses the efficiency of fuel use in the Navy Ships to reduce the rate of global warming, the research approach used in this study is to use a quantitative analysis approach. The quantitative approach is used to be able to understand what is happening to the object of research by providing quantitative descriptions and explanations in the form of dimensions, numbers that are measurable and clear. This research was conducted with a quantitative approach to the reconfiguration of the thrust system and the redesign of the management of the ship's electrical load to improve the efficiency of fuel use to reduce the rate of global warming. This research is analytic to empirical objects whose boundaries are clear and can identify the related factors in it.

The quantitative approach always begins with the identification of problems which then change and develop into clear, which is then carried out data processing, analysis, and data formulation to produce conclusions following the research objectives. The measured meaning is continuously explored from the interaction of variables that continue throughout the research period. This research continuously observes, measures, and processes data to find answers to problems that arise.

In this study, the research instrument is in the form of a simulation, the theoretical or experimental guide for the process of data collection and variable formulation. Before being used as an instrument, it is necessary to do a validation and reliability test of the instrument. Furthermore, after the data collected is processed and analyzed the results of data processing. Furthermore, it is conducted to deepen and interpretation of the results and conclusions that make a real contribution to the development of science and technology, especially in the field of environmental science.

The object in this study is focused on ships that can represent the condition of the reconfiguration of the ship's propulsion system, the management of the ship's electrical load, and the efficiency of fuel use to reduce the rate of global warming, aspects of national defense at sea and maritime aspects, one of which is the Republic of Indonesia Warship.

The place or location of the study was chosen purposively according to the needs of this study, which included: Kotama Operations and Educational Institutions, namely Fleet Command II (Koarmada II), and the Indonesia Naval Technology College (STTAL). The reason for choosing the place and location of the research is because it is quite appropriate to represent the conditions in carrying out the test of the reconfiguration of the ship's support system and the management of the ship's electricity load, as well as the efficient use of fuel in terms of operational institutions (Koarmada II) and higher education institutions, Indonesia Naval Technology College (STTAL).

When this research was conducted from January 2020 to December 2021. Data collection in the form of simulations, direct measurements in the field, observations, and questionnaires (if needed) as well as literature studies conducted during this period. For variable data and criteria that are qualitative and have a preference value, it is taken from the expert judgment. The expert judgments as research subjects were chosen because they are very knowledgeable about the problems regarding the configuration of the ship's propulsion system, the management of the ship's electrical loads and the efficient use of fuel, aspects of national defense at sea as well as maritime and competent aspects in their fields. Validation of the results of data processing also needs to be done in this dissertation research to obtain valid and objective data.

In this study, the type of data consists of two types, namely primary data types and secondary data sources. Primary data types are original data sources, i.e. data where data is collected directly by researchers for specific research or project purposes. Primary data can be collected in various ways. However, the most common techniques are selfmanaged surveys, measurements, field observations, and experiments. Primary data collection is quite expensive and time consuming compared to secondary data collection. Nevertheless, primary data collection is a single alternative that is suitable for several types of research (Johnston, 2014). Secondary data is data collected by others for other primary purposes. The utilization of existing data provides the right choice for researchers who have limited time and resources. Secondary analysis is an empirical exercise that applies the same basic research principles as studies that use primary data and has several steps to be followed just like other research methods (Johnston, 2014). There are also several 
secondary data sources derived from books, journals, planning policies (Jakren), and a compilation of regulations related to research.

Data is only meaningful if analyzed accurately and thoroughly. Data analysis is the process of capturing/describing and compilation of transcripts and other materials that have been collected. Quantitative analysis is an analysis that is used to discuss and explain the results of research on various symptoms or cases that can be described with descriptions of numbers that can be measured clearly and also requires a quantitative description and description (Morra Imas \& Rist, 2009). The data obtained are numeric and can provide information and explanations of quantitative research results.

Data is material information or a collection of objects of research that emphasizes more on the material aspects, everything that only relates to information about a fact found by researchers in the study area so that a conclusion can be drawn. The data in this study consisted of main data and supplement data. The main data is data obtained directly utilizing measurement, observation, and interviews. While supplement data is data obtained indirectly. The method of collecting data is by looking at some literature, including notes, books, and supporting documents such as maps, graphs, etc. that are connected with observational and questionnaire data. Data collection in this dissertation research activity is to obtain data consisting of primary and secondary data obtained by conducting direct interviews with relevant agencies and also with observations in the field. The process of collecting main data and supplement data in this study was carried out through the following activities:

- Library / Documentation Study. (Library Research). A literature study is carried out by analyzing and comparing several books to obtain theoretical data as primary data consisting of theories about the reconfiguration of the ship's propulsion system, the management of the ship's electrical load, and the efficiency of fuel use to reduce the rate of global warming, aspects of national defense at sea and maritime aspects. Data collection using documentation techniques is carried out to collect and identify existing data and information at the data source, which is considered to be able to answer research questions.

- Questionnaire (if needed). Data collection techniques using questionnaires and questionnaires carried out by giving a set of questions or written statements to respondents in the unit of analysis. This questionnaire technique is mainly focused on capturing data about the perception conditions of stakeholders, institutions, and users or technical users related to the reconfiguration of the ship's propulsion system, the management of the ship's electricity load, and the efficient use of fuel on the Navy Ships to reduce the rate of global warming.

- Direct Observation and Measurement. Direct observation and measurement is a data collection technique that is carried out through direct observation and measurement of objects or research samples. Direct observation and measurement activities in this study were conducted to capture data in the form of fuel efficiency conditions in the Navy Ships to reduce the rate of global warming.

\section{The Conceptual of Re-Design Steps and Frame Work of Research}

The conceptual design steps and framework of this study can be presented in Figure 1 below: 


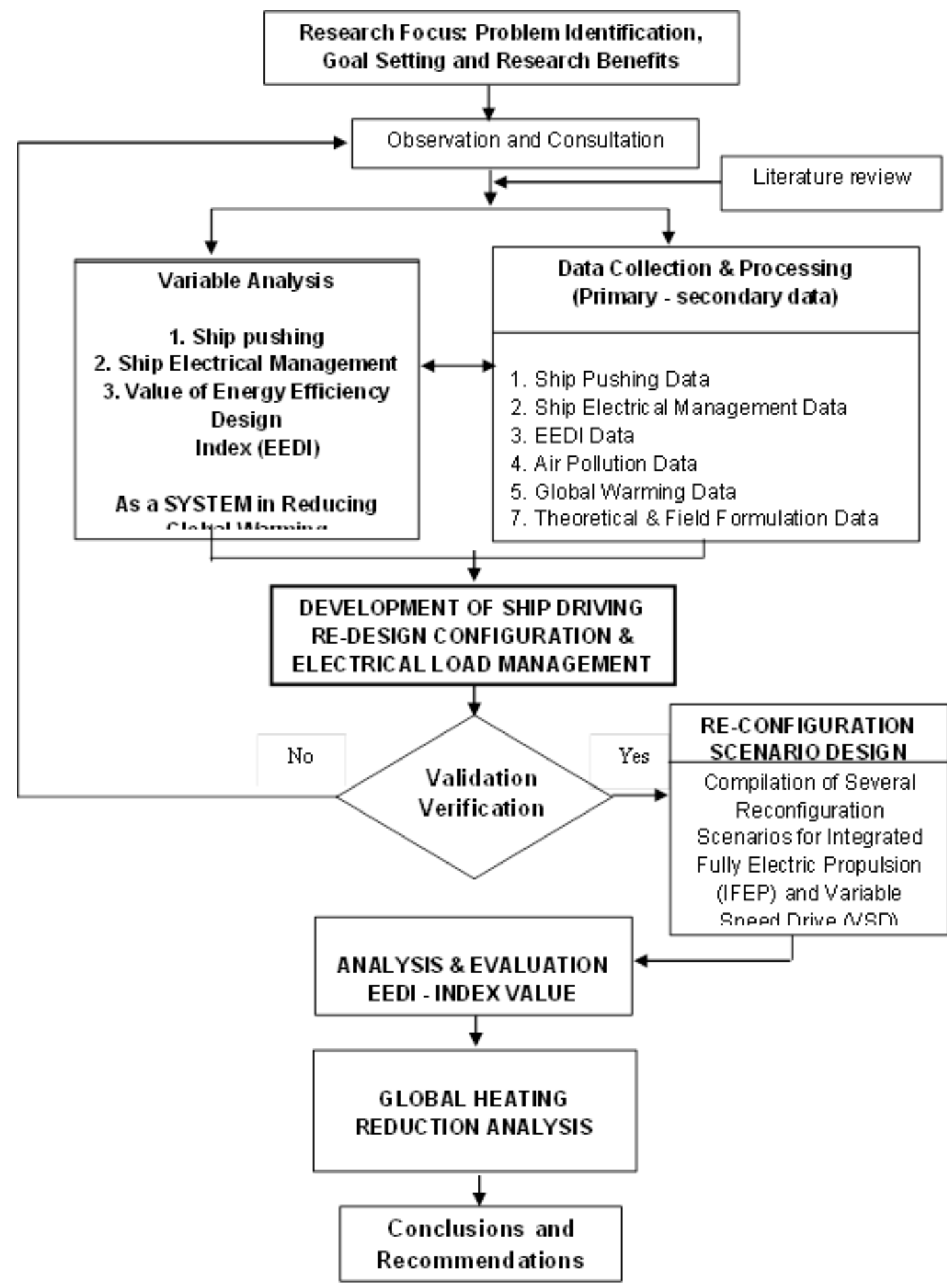

Figure 1 The Conceptual of Re-Design Steps and Frame Work of Research

\subsection{The Conceptual of Re-Design Propulsion System And Ship Electricity Management}

The Conceptual of Re-Design Propulsion System and Ship Electricity Management stages and data analysis and in this study are shown in Figure 2 which includes:

- Understanding the complexity of the system configuration of the propulsion system and the management of the ship's electricity load, the efficiency of fuel use, and the reduction in the rate of global warming.

- Identification and definition of problems in the vessel support and reconfiguration management system.

- Conceptualizing the Re-Design Configuration system. 
- Formulation of the Re-Design Configuration model

- Perform simulations and validations.

- Analysis and evaluation of the Energy Efficiency Design Index (EEDI) output

- Analysis of potential implementation in the field according to real conditions.

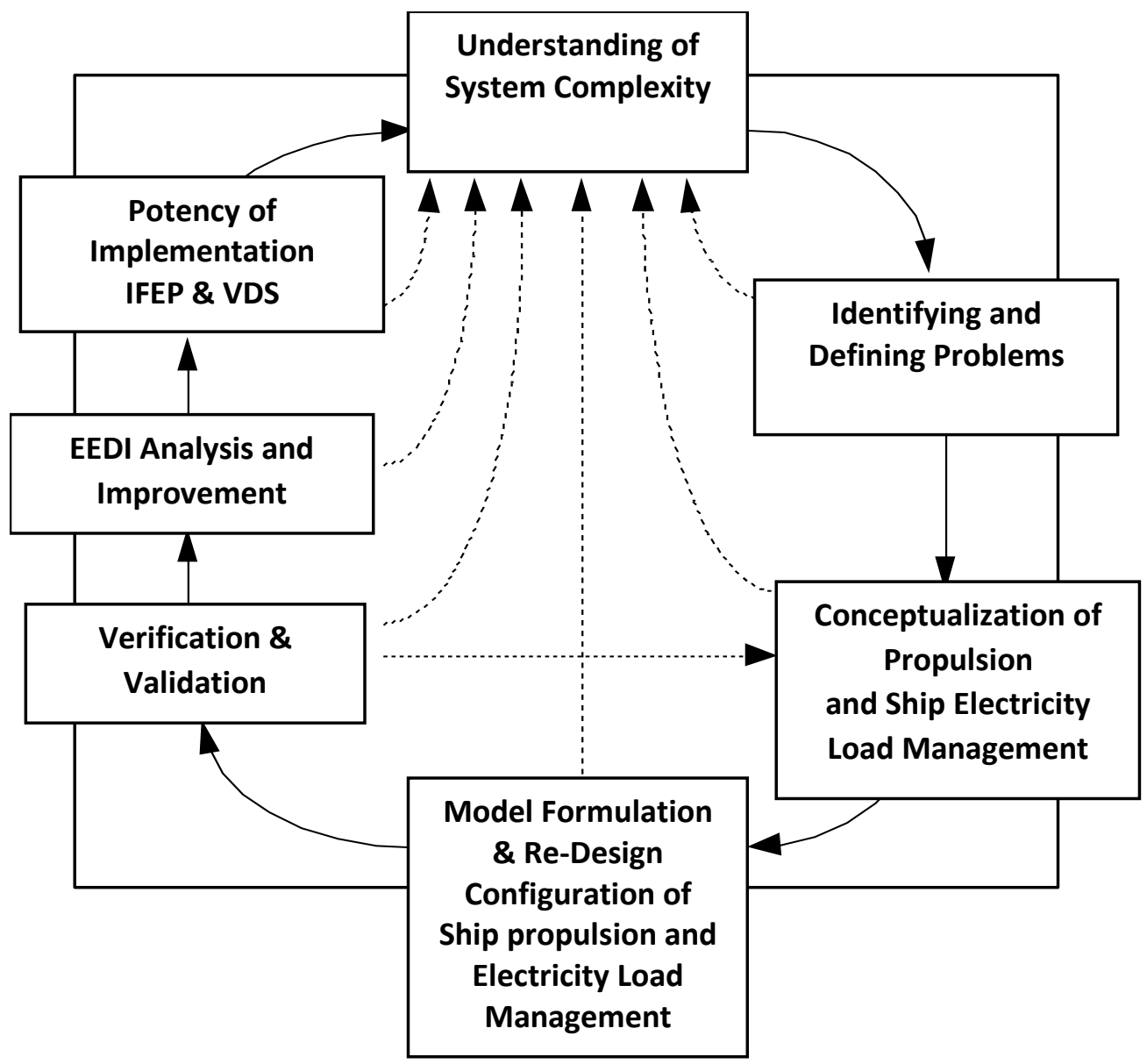

Figure 2 The Conceptual of Re-Design

The data analysis process is based on the simplification and interpretation of the data that is carried out before, during, and after the data collection process. This process consists of three interrelated sub-processes, namely data reduction, data display, and conclusion drawing/verification. In this research, data processing is carried out continuously, that is during the course of the study and after the research in the field. This is intended to select the data that is needed and support the problems and topics that are the focus of research.

\subsection{The Conceptual of Energi Efficiency Design Index (EEDI)}

The Energy Efficiency Design Index (EEDI), formulated for new ships, is an index that estimates grams of CO2 per transportation work (g CO2 per ton-mile). Or it can be stated as the ratio of "environmental costs" divided by "Benefits for the Community". The equation can be stated as follows:

$$
\begin{gathered}
E E D I=\frac{E M I S S I O N \text { of CO2 }}{\text { TRANSPORTATION WORK }} \\
E E D I=\frac{\text { Enviroment Cost }}{\text { Benefits for Society }}
\end{gathered}
$$


The philosophy behind EEDI is that the calculations are simple and can be widely applied. This is expected to stimulate further technical development aspects on all components of the ship which will result in more efficient use of fuel on the ship.

\subsection{The Conceptual of Ship Electricity Load Management}

One of the main work support systems on a ship is an electrical system which generally consists of resources, distribution systems, and electrical equipment. The electric power available is used to meet the needs of existing equipment on board. To keep all operations onboard to remain safe and following their functions, the electric power provided by the generator must be adequate. The generator as the main electrical power provider for all electrical equipment installed must be able to work continuously.

Electrical equipment on board, in general, can be grouped into several parts, namely, lighting, navigation communication systems, and electrical equipment supporting the work system on board. In the ship's electrical system this equipment can be referred to as a load, where the load must be met by the generator to operate according to function. Loads in the ship's electrical system are mainly supplied by generators. Electric power generated by the main generator will be centered on the main switchboard (MSB) while the electric power generated by the emergency generator will be centered on the emergency switchboard (ESB) before being distributed to equipment that requires electrical power.

Ship's electrical load management is a system that has the functions of controlling and monitoring all generators as the main electrical power provider for all electrical equipment or installed loads. The total load that must be borne by the generator depends on the amount and intensity of the load itself. The amount of the total load can be determined through the Power Management System (PMS) to determine the number of generators that must operate.

\section{Conclusion}

Based on the quantitative analysis approach that has been implemented, the Concept of Re-Design of Supporting System And Ship Electricity Management To Reduce Waste Emission is produced to reduce fuel use. By implementing this system, it will increase the efficiency of fuel use and reduce air pollution so that the Indonesian Navy can contribute greatly to participating in overcoming environmental problems. Furthermore, the results of this study can be used as material for consideration of the Indonesian Navy leadership in determining policies for the use of Design Of Supporting System And Ship Electricity Management.

\section{Future Work}

The output of this study is limited to the drafting a conceptual model of Re-Design Of Supporting System and Ship Electricity Management To Reduce Waste Emission so that this research can be continued and can be further developed in the direction of calculating and deep more analysis about parameter and variable that related to increase the efficiency of fuel use and reduce air pollution with the sector of supporting system and electricity management.

\section{Compliance with ethical standards}

\section{Acknowledgments}

The authors greatly acknowledge the support from the University of Brawijaya Malang, the Indonesian Naval Technology College STTAL and the Indonesian Navy Institution for providing the necessary resources to carry out this research work. The authors are also grateful to the anonymous reviewers and journal editorial board for their many insightful comments, which have significantly improved this article.

\section{Disclosure of conflict of interest}

The authors declare no conflict of interest.

\section{References}

[1] Alisafaki AG, Papanikoloau AD. On The Energy Efficiency Design Index of Ro-Ro Passenger and Ro-Ro Cargo ships. Journal of Engineering for the Maritime Environment. 2015; 1-12. 
[2] Boulougoris E, Papanikoulaou A, A Pavlou. Energy Efficiency Parametric Design Tool in The framework of Holistic ship design Optimization. Journal of Engineering of Maritime Environment. 2011; 225.

[3] Calligaro S. A Fully-Integrated Fault-Tolerant Multi-Phase Electric Drive for Outboard Sailing Boat Propulsion. Journal of Applied Energy. 2018.

[4] Chaia M. Alternating current and direct current-based electrical systems for marine vessels with electric propulsion drives. Applied Energy. 2018.

[5] Jeong B. Multi-criteria decision-making for marine propulsion: Hybrid, diesel-electric, and diesel mechanical systems from cost-environment-risk perspectives. Journal International Applied Energy. 2018.

[6] Lindstad E, Ingebrigtsen T. Potential power setups, fuels, and hull designs capable of satisfying future EEDI requirements. Transportation Research. 2013.

[7] Malaria F, Jebai Ak, Ejjabraui K. Power conversion optimization for a hydraulic system controlled by variable speed drives. Journal of Process Control. 2019.

[8] Mashud M, Karim, Hasan R. Establishment of EEDI Baseline for Inland Ship of Bangladesh. Procedia Engineering. 2017.

[9] Nel AJ, Arndt DC, Karim Vosloo JC, Mathews MJ. Achieving energy efficiency with medium voltage variable speed drives for ventilation-on-demand in South African mines. Journal of Cleaner Production. 2019.

[10] Saidur R, Mekhilef S, Ali MB, Safari A, Mohamed H. Application of Variable Speed Drives (VSD) in electrical motors Energy Savings. Renewable and Sustainable Energy. 2012; 543-550.

[11] Schibuola L, Scarpa M, Tambani C. Variable speed drive (VSD) technology applied to HVAC systems for energy saving: an experimental investigation. 73rd Conference of the Italian Thermal Machines Engineering Association. 2018.

[12] Sequeira M, Alakoon S. Energy-efficient variable speed drives empowered with torque estimation. Journal of Energy Procedia. 2019.

[13] Zakaria NG, Rahman S. Energy Efficiency Design Index (EEDI) for Inland Vessels in Bangladesh. Procedia Engineering. 2017.

[14] Zhu Y, Zhou S, Feng Y, Hu Z, Yuan L. Influences of solar energy on the energy efficiency design index for new building ships. International Journal of Hydrogen Energy. 2017; 19389-19394. 